\title{
INFLUÊNCIA DA DIETA, SEXO E GENÓTIPO SOBRE O PERFIL LIPÍDICO DA CARNE DE OVINOS
}

\author{
INFLUENCE OF DIET, SEX AND GENOTYPE ON THE LIPID PROFILE OF SHEEP MEAT
}

\author{
Oliveira, A.C. ${ }^{1 *}$; Silva, R.R. ${ }^{2}$; Oliveira, H.C. ${ }^{3} ;$ Almeida,V.V.S. ${ }^{4}$; Garcia, R. ${ }^{3}$ \\ e Oliveira, U.L.C. ${ }^{2}$
}

\begin{abstract}
${ }^{1}$ Universidade Federal de Alagoas (UFAL). Arapiraca-AL. Brasil. oliveyra_aline@yahoo.com.br ${ }^{2}$ Universidade Estadual do Sudoeste da Bahia (UESB). Itapetinga-BA. Brasil.

${ }^{3}$ Universidade Federal de Viçosa. Departamento de Zootecnia(UFV). Viçosa-MG. Brasil.

${ }^{4}$ Instituto Federal de Educação, Ciência e Tecnologia Baiano (IFBAIANO). Santa Inês-BA. Brasil.
\end{abstract}

\section{PalaVRas chaVe adicionais}

Ácidos graxos. Gordura. Raças. Alimentação.

\section{RESUMO}

Nos dias atuais o perfil dos consumidores têm modificado, principalmente quando se trata de aspectos ligados á saúde. Diante dessa iminente preocupação diversos pesquisadores em todo o mundo despertaram o interesse em modificar o perfil lipídico da carne de ruminantes, uma vez que a gordura se tornou um componente impopular da carne. Ë sabido que a composição de ácidos graxos nos ruminantes pode ser influenciada por fatores de ordem interna (sexo, genética), como por fatores externos aos animais como manejo alimentar e dieta. A manipulação da dieta é o fator que mais exerce influência sobre o perfil de ácidos graxos de carne de cordeiros. Nesse sentido o principal foco desta revisão é abordar os efeitos desses fatores sobre a composição de ácidos graxos de ovinos.

\section{SUMMARY}

Nowadays the consumers have changed, especially when it comes to issues related to health. Faced with this imminent concern many researchers around the world have raised interest in modifying the lipid profile of meat from ruminants, once the fat has become an unpopular part of the meat. It is known that the fatty acid composition in ruminants may be influenced by internal (sex, genetics) and external factors to animals as feed management and diet. The manipulation of diet is

\section{AdDitionAL KEYWORDS}

Fatty acids. Fat. Breeds. Feeding. the most important factor that influences the fatty acid profile of lamb. In this sense the main focus is to address the effects of these factors on the fatty acid composition of sheep.

\section{INTRODUÇÃO}

Atualmente, a busca por alimentos saudáveis têm despertado o interesse dos consumidores, em decorrência da modificação comportamental da população consumidora, o oferecimento de produtos consideráveis saudáveis tem estimulado diversos pesquisadores a tentar manipular a composição dos alimentos, principalmente aqueles que mais estão relacionados a problemas cardíacos.

Nesse panorama a gordura, componente considerado impopular pelos consumidores atuais que relacionam seu consumo com hábitos de vidas insalubres, também contribuem como fator importante para vários aspectos da qualidade da carne, sendo também fundamentais para o valor nutricional da mesma (Webb e O’Neill, 2008).

Diante disso, é imprescindível considerar que embora a intenção de produção de alimentos funcionais seja uma tendência 
atual, quando se trata do alimento carne, mais especificamente de ruminantes essas modificações e/ou manipulações de sua composição apresentem uma série de particularidades a exemplo da biohidrogenação ruminal (Costa et al., 2008).

Nesse sentido, vários fatores influenciam tanto a quantidade como a qualidade dos lipídios em produtos de origem animal (Kouba e Mourota, 2011). Os fatores internos, como sexo, genótipo, têm influência sobre a quantidade de lipídios nesses produtos (Sañudo et al., 1997; Nürnberg et al., 1998). Fatores externos como alimentação tem uma influência sobre a composição de ácidos graxos de lipídios, sendo considerado um fator de extrema importância quando se trata da manipulação da composição de ácidos graxos da carne (French et al., 2000; Cooper et al., 2004; Nuernberg et al., 2008).

Considerando os fatores que influenciam o perfil de ácidos graxos da carne, a busca pela elevação da proporção de ácidos graxos considerados saudáveis têm sido estudado de forma contínua nos últimos anos. Diante disso o principal foco desta revisão é abordar os efeitos do sistema de alimentação, sexo e da genética sobre a composição de ácidos graxos de ovinos.

\section{INFLUÊNCIA DO SISTEMA DE ALIMENTAÇÃO NA COMPOSIÇÃO DE ACIDOS GRAXOS}

A qualidade da carcaça e da carne ovinos depende de vários fatores, dentre eles a composição de ácidos graxos (AG), sendo esta influenciada pela dieta, sexo, raça e idade do animal (Choi et al., 2000; Zembayashi et al., 1995). Normalmente, a gordura de animais terminados a pasto apresenta um teor mais elevado de AG poliinsaturados (AGPI) em relação à gordura oriunda de animais confinados, apesar da biohidrogenação ocorrida no rúmen. Isto se deve ao alto conteúdo de AG $\omega$-3 (C18:3) presente nas forragens, enquanto que os grãos são normalmente ricos em AG $\omega-6$
(C18: 2) ( Raes et al., 2003; Wood et al., 2003).

Existem evidências dos benefícios do AG $\omega$-3 na prevenção de doenças cardiovasculares e do câncer em humanos, em contraste ao efeito oposto provocado por alguns AG $\omega$-6 (Laborde et al., 2001). De acordo com Wood et al. (2003), a taxa de AGPI $\omega-6 / \omega-3$ é particularmente baixa na carne de ruminantes, especialmente de animais alimentados com forragens contendo altos níveis de C18:3, sendo benéfica à saúde humana. Para os animais alimentados à base de grãos, esta relação $\omega-6 / \omega-3$ pode ser reduzida através da suplementação na dieta com alimentos ricos em ácido linolênico ( $\omega$-3), principalmente se esses AG forem protegidos da biohidrogenação ruminal.

Nos ruminantes, a composição dos AG da carne é influenciada em maior extensão, por fatores dietéticos. De acordo com French et al. (2000) há indícios de que o tipo de dieta fornecida ao animal altera o perfil de lipídeos da carcaça dos animais, o que permitiria manipular a composição da fração gordurosa, através do uso, por exemplo, de sementes oleaginosas. Em contrapartida, o metabolismo ruminal modifica o perfil dos ácidos graxos da gordura da dieta disponíveis para absorção intestinal e a biohidrogenação no rúmen (figura 1) influencia a digestibilidade da gordura, sendo o principal fator determinante do perfil de ácidos graxos saturados constituintes da gordura corporal dos ruminantes (Jenkins, 1993; Palmquist, 1993). Nesses animais parte dos ácidos graxos insaturados provenientes da dieta é saturada por meio de um processo de biohidrogenação no ambiente ruminal, como forma de neutralizar seu efeito tóxico aos microorganismos ruminais. Como resultado desse processo, a classe dos ácidos graxos saturados é absorvida e incorporada ao tecido muscular (Costa et al., 2008).

A carne de ovinos é considerada rica 
Cis 9 , cis-12, cis-15 (ácido $\alpha$-linolênico, $\mathrm{C}_{18: 3}$ )

\section{§ Reação de isomerização (Grupo A e B)}

Cis 9 , trans -11 cis- 15

$$
\text { \. Hidrogenação (Grupo B) }
$$

Trans - 11 cis- 15 (ácido Octadecanóico, $\mathrm{C}_{18: 2}$ )

$\sqrt{ }$

Trans-11 (ácido Octadecanóico, $\mathrm{C}_{18: 1}$ ) $\Delta-9$ dessaturase

\Hidrogenação (Grupo B)

\section{Ácido estérico $\left(\mathrm{C}_{18: 0}\right)$}

Figura 1. Biohidrogenação do ácido linolênico pelas bactérias ruminais. Adaptado de Harfoot e Hazlewood (1997). (Linolenic acid biohydrogenation by ruminal bacteria. Adapted from Harfoot and Hazlewood, 1997).

em ácidos graxos saturados, pois os microrganismos do rúmen hidrogenam extensivamente os ácidos graxos da dieta. Os ácidos graxos mais encontrados nesta espécie são o mirístico (2,04 \% - 3,65 \%), o palmítico (20,88 \% - 24,22 \%) e o esteárico (11,89\% - 15,09 \%); os monoinsaturados são o palmitoléico $(2,23 \%$ - 2,54 \%) e o oléico $(31,74 \%$ - 45,23 \%) e os poliinsaturados são o linoléico (4,73 \% -10,39 $\%)$, o linolênico $(0,43 \%-2,84 \%)$ e o araquidônico (1,14 \% - 6,7 9 \%) (Pérez et al., 2002).

Em cordeiros terminados com concentrado ou forragem, os ácidos graxos poliinsaturados da dieta são biohidrogenados no rúmen, resultando na absorção predominante de ácidos graxos saturados pelo intestino. Este é um dos motivos pelo qual a carne ovina é caracterizada por alta concentração de ácidos graxos saturados e baixa relação de ácidos graxos poliinsaturados:saturados (P:S) (Cooper et al., 2004).
Inúmeras pesquisas demonstram a importância da dieta como fator determinante para caracterizar possíveis variações na carcaça e na composição tecidual e química dos cortes comerciais (Raes et al., 2004; Boles et al., 2005; Bass et al., 2007; Gallo et al., 2007). Neste contexto os fatores que podem determinar maior ou menor variação são: diferentes proporções de concentrados e volumosos, assim como sistema exclusivo em pastejo ou em confinamento, diferentes fontes de volumosos, diferentes fontes de concentrado entre outros.

Diante disso, Boles et al. (2005), alimentaram cordeiros com dietas contendo $80 \%$ de concentrado e níveis crescentes de óleo de açafrão (0, 3 e $6 \%$ ), verificaram que a suplementação até $6 \%$ na dieta, resultou em aumento nos níveis de ácidos graxos insaturados e CLA no tecido muscular, sem afetar a performance de crescimento, as características da carcaça ou a estabilidade da cor da carne dos carneiros. Segundo os 


\section{OLIVEIRA, RODRIGUES, OLIVEIRA, ALMEIDA,GARCIAE OLIVEIRA}

autores, esta descoberta sugere que o aumento nos níveis de alimentos precursores de CLA em animais ruminantes, pode resultar em um aumento do conteúdo de CLA, bem como aumento de ácidos graxos poliinsaturados na carne.

O cis-9, trans-11 C18:2 é o principal isômero de CLA presente na carne e no leite de ruminantes, mas sua concentração, assim como do trans-10, cis-12 C18:2 e outros isômeros, varia dependendo da dieta que os animais estão consumindo (Pariza et al., 2001). A produção de ácido linoléico conjugado (CLA) é maior em animais criados a pasto, mas dificilmente ultrapassa os 20 $\mathrm{mg} / \mathrm{g}$ gordura, porém dietas a base de feno e grãos podem ter o valor de CLA ultrapassando esse valor por suplementos contendo ácido linoléico.

$\mathrm{O}$ interesse pelo aumento das concentrações do CLA tem ocorrido devido às suas propriedades bioativas. No entanto, grande parte do trabalho tem sido realizado com animais e testes em humanos geralmente têm sido inconclusivos até agora (Tricon et al., 2005).

O consumo diário de CLA no homem ocidental é estimado em apenas $1 \mathrm{~g}$, embora esteja sendo recomendada a ingestão de 3,5 g de CLA/dia para um homem adulto de 70 kg. Assim, a suplementação de CLA na dieta do ser humano faz-se necessária para alcançar essa recomendação (Ip et al., 1994). O aumento na concentração de CLA nos alimentos provenientes de ruminantes (leite e carne) pode ser benéfico para a saúde pública promovendo aumento no consumo destes alimentos.

Embora Khanal e Dhiman (2004) reconheçam muitos isômeros de CLA presente no leite e no tecido adiposo de ruminantes, Parodi (2003), avaliou que apenas dois desses isômeros desempenhavam importantes atividades fisiológicas. $\mathrm{O}$ isômero C18:2 c9,t11 aparece em maior concentração nos produtos originários dos ruminantes, podendo atingir até $90 \%$ do montante de CLA presente, e o C18:2 t10,c12, apresenta- se em pequenas quantidades, representando apenas 3 a $5 \%$ do CLA total.

Raes et al., 2004 , em uma revisão dos efeitos dos ácidos graxos das dietas sobre a incorporação de n-3 PUFA e CLA em carne, relatou que alto teor de n-3 PUFAs na ração animal aumentou o teor de CLA na carne de cordeiro. A faixa do teor de CLA da carne de ruminantes, no entanto, foi 0, 2-1 g/ $100 \mathrm{~g}$ ácidos graxos totais, sendo muito menor do que o obtido no leite, como foi observado mais tarde.

Segundo Velasco et al., (2004), a composição da gordura de cordeiros amamentados é a mesma do leite materno, mas pode ser modificada pelo consumo de alimento complementar. Estes autores trabalharam com cordeiros desmamados e mantidos com suas mães recebendo dieta completa ou cevada. Os cordeiros que receberam concentrado tiveram mais gordura do que os que receberam forragem. Os autores observaram que nos cordeiros desmamados a proporção concentrado/ volumoso modificou a proporção de ácidos graxos no tecido adiposo. Com referência ao efeito da desmama, os ácidos graxos de cadeia média como o mirístico (C14:0) e o palmítico(C16:0) predominaram em cordeiros não desmamados e o heptadecanoico (C17:0), esteárico e oléico predominaram em cordeiros desmamados. Além disso, cordeiros mantidos com suas mães tiveram mais gordura na carcaça do que desmamados e a proporção de gordura intramuscular do músculo Longissimus foi ligeiramente maior para cordeiros desmamados em relação aos que permaneceram com as mães.

Macêdo et al. (2008) o estudarem o perfil de ácidos graxos da carne de cordeiros, Gallo et al.(2007), verificaram que as concentrações dos saturados pentadecanóico (C15:0), palmítico (C16:0) eheptadecanóico (C17:0), dos monoinsaturados palmitoléico (C16:1) e oléico (C18:1) e do poliinsaturado linolênico (C18:3) foram influenciadas pelo sistema de terminação (tabela I). As carnes dos animais terminados em pasto e a dos 
Tabela I. Perfil de ácidos graxos do músculo Triceps brachii de cordeiros. (Fatty acid profile of muscle Triceps brachii of lambs).

\begin{tabular}{lccc}
\hline \multirow{2}{*}{$\begin{array}{c}\text { Ácido } \\
\text { graxo }\end{array}$} & \multicolumn{3}{c}{ Sistema de terminação } \\
& Dieta completa & Feno & Pastagem \\
\hline C12:0 & 1,18 & 1,65 & 1,53 \\
C14:0 & 7,15 & 8,91 & 8,14 \\
C15:0 & $0,71^{\mathrm{a}}$ & $1,36^{\mathrm{c}}$ & $0,97^{\mathrm{b}}$ \\
C16:0 & $28,98^{\mathrm{b}}$ & $27,78^{\mathrm{a}}$ & $28,00^{\mathrm{a}}$ \\
C17:0 & $1,17^{\mathrm{a}}$ & $1,72^{\mathrm{b}}$ & $1,34^{\mathrm{a}}$ \\
C18:0 & 14,03 & 15,85 & 16,70 \\
C16:1 & $2,30^{\mathrm{b}}$ & $1,83^{\mathrm{a}}$ & $1,86^{\mathrm{a}}$ \\
C18:1 & $38,01^{\mathrm{b}}$ & $34,23^{\mathrm{a}}$ & $34,83^{\mathrm{a}}$ \\
C18:2 & 5,59 & 4,44 & 5,36 \\
C18:3 & $0,51 \mathrm{~b}$ & $1,42^{\mathrm{a}}$ & $0,88^{\mathrm{ab}}$ \\
Saturado & $53,62^{\mathrm{a}}$ & $58,02^{\mathrm{b}}$ & $57,04^{\mathrm{b}}$ \\
Insaturado & $46,37^{\mathrm{b}}$ & $41,97^{\mathrm{a}}$ & $42,95^{\mathrm{a}}$ \\
Relação I:S & $0,86^{\mathrm{b}}$ & $0,72^{\mathrm{a}}$ & $0,75^{\mathrm{a}}$ \\
\hline
\end{tabular}

Adaptado de Gallo et al. (2007). Médias com letras distintas na linha diferem $(p<0,05)$ pelo teste $t$.

que receberam apenas feno no confinamento tiveram maiores teores de ácidos saturados. A concentração do ácido poliinsaturado C18:3, também foi maior na carne dos cordeiros alimentados com feno, seguida pela dos terminados no pasto e dos confinados com dieta completa.

Nuernberg et al. (2008), ao avaliarem o efeito dos sistemas de terminação (pasto e confinamento), também verificaram que a concentração de ácidos graxos saturados foi maior na carne dos cordeiros terminados em pasto. Os sistemas de alimentação com base no consumo de forragens também aumentaram a porcentagem dos ácidos graxos da família dos $\omega 3$ na carne de cordeiros (Demirel et al., 2006; Nuernberg et al., 2008). Ao estudarem o perfil de ácidos graxos da carne de cordeiros terminados com relações volumoso:concentrado (75:25 e 25:75), Demirel et al. (2006) verificaram que na relação 75:25 produziu-se carne com maior concentração de $\omega 3$ e menor relação $\omega 6: \omega 3$. Estes resultados estão de acordo com
Nuernberg et al. (2008), que também verificaram que a relação $\omega 6: \omega 3$ foi menor na carne dos cordeiros terminados em pasto $(2,40)$, quando comparada à carne dos confinados $(3,20)$.

Estudos mostram que a gordura de cordeiros mantidos em pastagem, normalmente, apresenta adequada proporção de ômega-6/ômega-3 de ácidos graxos poliinsaturados do que observado para as mesmas gorduras de cordeiros no confinamento. Essa diferença é em virtude da composição de ácidos graxos da dieta, uma vez que as forragem contém alto nível de ácidos graxos linolênico (C18:3), precursor da série ômega-3 de ácidos graxos. O concentrado, ao contrário, tem alto teor de ácido linoléico (C18:2), precursor da série n6(Díaz et al., 2002).

Os ácidos graxos das famílias ômega-6 e ômega-3 têm ações diferentes no organismo humano enquanto os produtos metabólicos dos ácidos graxos ômega-6 promovem inflamação e tumores, os ácidos graxos ômega-3 atuam no sentido contrário. É importante manter um equilíbrio dietético entre os dois tipos de ácidos graxos, uma vez que funcionam em conjunto, promovendo a saúde e equilíbrio orgânico.

Wood et al. (2008) em revisão sobre deposição de gordura, composição de ácido graxo e qualidade de carne, relata que dietas com concentrados ricos em ácido linoléico (C18:2), favorecem o acúmulo desse ácido na carne, pois com a pequena dimensão das partículas e um trânsito mais curto no rúmen, limita a biohidrogenação pelos microorganismos o que favorece o escape desse composto para absorção no intestino. Os resultados obtidos por Bass et al., 2007 ao avaliarem os efeitos da suplementação com linhaça (0\%, L0, $3 \%$, L3, 6 \%, L6, $9 \%$, L9), durante o período de terminação em cordeiros machos e fêmeas alimentados com dietas ricas em concentrado, sobre a composição de ácidos graxos, ratificam a constatação supracitada, uma vez que os autores desta pesquisa verificaram que a 


\section{OLIVEIRA, RODRIGUES, OLIVEIRA, ALMEIDA,GARCIAE OLIVEIRA}

proporção de ácido linolênico aumentou linearmente com a semente de linhaça na dieta a partir de: 0,6 ; 0,5 e $0,5 \%$ para $\mathrm{L} 0$; 1,9 , 1,6 e 1,3\% para L9 na gordura perirenal (PR), subcutânea (SC), e Longissimus dorsi (LD), respectivamente. O aumento do n-3 PUFA e ácidos graxos poliinsaturados totais foi semelhante à do ácido linolênico a relação n-6: n-3 diminuiu de 5,7, 5,3 e 5,8 do controle L0, para 1,8, 1,7 e 2,7 para a L9, no PR, SC e $\mathrm{LD}$, respectivamente.

Ao estudarem o perfil de ácidos graxos em concentrados e volumosos utilizados em região tropical, Fernandes et al. (2007) observaram na cana-de-açúcar e no capim elefante, teores elevados de ácidos linoléico e linolênico, que totalizaram 58,80 \% e 55,70 \%, respectivamente. Entretanto, é importante ressaltar que as plantas forrageiras produzem diferentes concentrações de ácidos graxos poliinsaturados na carne, devido ao maior ou menor nível destes, ou por diferenças no processo de digestão do alimento no rúmen (Wood et al., 2008).

Em pesquisa sobre a influência de dois sistema de manejo alimentar (pastagens ou concentrado), sobre o perfil de ácidos graxos de cordeiros Churra Tensina, Joy et al.(2008), verificaram que a porcentagem de ácidos graxos não foi afetado pelo tratamento embora o percentual de C18:3 (1,91 vs 1,72$)$ se apresentasse maior, a proporção de C18:2/C18:3 (5,04 vs 6,08) foi menor nos cordeiros alimentados com pastagens. Embora o tratamento não tenha influenciado a taxa de C18:2/C18:3, de cordeiros alimentados em pastagens estes apresentaram uma relação 21 \% menor, o que sugere que esta carne era mais saudável do que a de cordeiros alimentados com concentrado. Segundo os autores a ausência de qualquer efeito do tratamento sobre os o percentual de ácidos graxos pode ser influenciada pela mesma quantidade de gordura intramuscular em ambos os tratamentos.

Ausência de mudanças significativas na gordura intramuscular pode estar rela- cionada ao fato de que durante a terminação ocorre um período de aumento do tecido adiposo subcutâneo em um ritmo superior a outros depósitos de gordura, como intramuscular (Demeyer e Doreau, 1999). Por outro lado, a gordura subcutânea parece ser mais sensível às mudanças na oferta de ácidos graxos na dieta ou mudanças no metabolismo do rúmen que a gordura intramuscular (Demirel et al., 2004; Wachira et al., 2002).

Fernandes et al. (2010), ao avaliarem a influência de quatro sistemas de terminação (pastagem, pastagem + mãe, pastagem + creep feeding + mãe e confinamento) na composição tecidual da carcaça e no perfil de ácidos graxos da carne de cordeiros, não observaram efeito do sistema de terminação sobre o perfil de ácidos graxos da carne. Entre os ácidos identificados na gordura intramuscular, houve predominância de cinco (ácido mirístico, C14:0; ácido palmítico, C16:0; ácido esteárico, C18:0; ácido oleico, C18:1 $\omega 9$; ácido linoleico, C18: $\omega 2)$, que representaram em média $88 \%$ do total, sendo que apenas o ácido esteárico (C18:0) foi influenciado pelas diferentes dietas. $\mathrm{O}$ ácido oléico (C18:1 $\omega 9$ ) foi o ácido graxo insaturado que mais contribuiu para a composição total dos ácidos, enquanto os ácidos palmítico (C16:0) e esteárico (C18:0) contribuíram mais entre os saturados.

De forma semelhante, Madruga et al. (2005) ao estudarem a influência de quatro tipos de alimentos volumosos (feno de capim-d’água + concentrado, feno de restolho de abacaxi + concentrado, palma + mistura, silagem de milho + concentrado) sobre os aspectos qualitativos da carne de ovinos Santa Inês, constataram que entre o total de ácidos graxos identificados, seis ácidos graxos (C18:1, C18:0, 16:0, C18:2, C16:1 e C18:2) constituíram acima de $90 \%$ dos AG totais. O ácido oléico (C18:1) foi o ácido graxo insaturado que mais contribuiu para o perfil dos ácidos graxos, enquanto os ácidos palmítico (C16:0) e esteárico (C18:0) contribuíram mais intensamente entre os 
ácidos graxos saturados. Segundo os autores as somas dos ácidos graxos saturados e a dos ácidos graxos poliinsaturados sofreram influência significativa das diferentes dietas testadas, sendo que os ovinos alimentados com palma forrageira apresentaram os somatórios mais elevados para os ácidos graxos saturados (50,51 \%) e poliinsaturados (5,01\%).

O ácido esteárico diferentemente dos outros ácidos graxos saturados atua na redução do colesterol sérico em humanos (Bonanome e Grundy, 1988). Esta redução promovida pelo ácido esteárico pode ser explicada pela diminuição da absorção de colesterol e aumento da excreção do colesterol endógeno.

Aumentar o conteúdo de ácidos graxos poliinsaturados nos tecidos de ruminantes por meio da alimentação é difícil devido à extensa hidrogenação de ácidos graxos insaturados da dieta pelos microorganismos ruminais. Mas, tem sido demonstrado que o conteúdo de ácidos graxos poliinsaturados no músculo de cordeiro (Demirel et al., 2004) pode ser aumentada pela administração de ácidos graxos poliinsaturados.

A suplementação com oleaginosas pode alterar a composição de ácidos graxos em ruminantes. Tem sido demonstrado por Wood et al. (1999) que a suplementação dietética de ácidos graxos poliinsaturados por oleaginosas pode, em parte, evitar a biohidrogenação de ácidos graxos insaturados da dieta pelos microorganismos ruminais.

Macêdo et al. (2008) ao avaliarem a composição tecidual e química do músculo Longissimus dorsi de cordeiros Suffolk alimentados com ração contendo 0; 6,60; 13,20 ou $19,80 \%$ de semente de girassol, observaram comportamento linear decrescente para ácido graxo palmítico (C16:0) que apresentou valor médio de 22,82 e comportamento crescente para ácidos graxos oléico (C18:1) e linoléico (C18:2) que apresentaram valores médios de 44,04 e 12,61 respectivamente. Diante dos resultados os autores concluíram que a semente de girassol altera o perfil de ácidos graxos do músculo Longissimus dorsi, ocasionando diminuição do ácido graxo saturado palmítico e aumento da insaturação da carne pelos ácidos graxos oléico e linoléico, o que melhora a qualidade da carne para consumo.

O tipo de gordura na dieta do homem é um importante determinante da concentração plasmática de lipídios (Caputi Jambrenghi et al., 2007). Alterando a composição de ácidos graxos dos alimentos, em especial aumentando a razão dos ácidos graxos poliinsaturados:saturados, representa uma forma útil para a prevenção de doenças e saúde em humanos (Caputi Jambrenghi et al., 2007). É sabido que as gorduras de cadeia saturada promovem um efeito hipercolesterolêmico, em especial da lipoproteína de baixa densidade (LDLcolesterol), no entanto o efeito hipercolesterolêmico das gorduras saturadas é obedecido basicamente pelos ácidos láurico, mirístico e palmítico, o contrário é observado pelos ácidos graxos insaturados em especial o ácido oléico (C18:1) (Farfan, 1996). Os ácidos graxos monoinsaturados, como o ácido oléico, têm poder redutor de colesterol e lipoproteína de baixa densidade (LDL). O ácido graxo poliinsaturado linoléico, no entanto, é considerado essencial, uma vez que não pode ser sintetizado pelos animais (Lehninger, 1990) e deve ser fornecido na dieta.

Madruga et al. (2008) ao avaliarem o efeito da inclusão (0, 20, 30 e 40 \%) de caroço de algodão integral (Gossypium hirsutum) na dieta sobre a composição química e o perfil de ácidos graxos da carne de cordeiros Santa Inês, constataram diferença entre os percentuais dos ácidos graxos mirístico, palmítico e linolênico e entre a relação C18:0 + C18:1/C16:0 que variaram de 2,10 a 4,34\%. O grupo dos animais que receberam a dieta adicionada de $30 \%$ de caroço de algodão integral foi o grupo que apresentou maior concentração do ácido palmítico $(26,91)$ comportamento inverso foi observado para 


\section{OLIVEIRA, RODRIGUES, OLIVEIRA, ALMEIDA,GARCIAE OLIVEIRA}

este nível para o ácido mirístico que apresentou valor $(0,31)$, inferior aos demais níveis. Quanto aos valores dos ácidos graxos desejáveis (AGD) estes variaram de 67,79 a $75,41 \%$.

Manso et al. (2009) ao investigar os efeitos da inclusão de $4 \%$ de óleo de palma hidrogenado (OPH) ou óleo de girassol(OG) no concentrado sobre a composição de ácidos graxos de cordeiros, constataram que o $\mathrm{OPH}$ não causou alterações significativas em relação ao grupo controle, a adição de OG para o concentrado diminuiu a proporção C16:0 e C18:1 foi significativamente maior e C18:1 cis-11 menor nos cordeiros OG quando em comparação com qualquer dos animais do grupo controle ou OPH. Quanto ao ácido linolênico (C18:3) a proporção baixou $4 \%$ quando o OG foi incluído no concentrado, o que levou a uma maior relação C18:2/ C18:3. Neste estudo a adição de OG no concentrado causou uma redução significativa na proporção de ácido palmítico (C16:0) na gordura subcutânea e intramuscular.

Arruda (2010) ao avaliar a influência de rações com diferentes níveis de energia metabolizável (2,08; 2,28; 2,47 e 2,69 Mcal/ kgMS) sobre perfil de ácidos graxos no músculo Longissimus dorsi de cordeiros Santa Inês, observaram que os ácidos graxos C16:0; C16:1; C18:0; C18:1; C18:2, constituíram mais de $90 \%$ das áreas totais do cromatograma. O ácido oléico (C18:1) foi o ácido graxo insaturado que mais contribuiu para o perfil dos ácidos graxos apresentando valores de (39,22; 33,7; 44,91 e 42,64) para os diferentes níveis de energia. Embora não tenham sido observadas variações significativas no perfil do ácido graxo oléico com o incremento de energia à ração, destaca-se que, cerca de $95 \%$ dos ácidos graxos monoinsaturados presentes no Longissimus dorsi dos cordeiros Santa Inês foram representados por esse ácido graxo.

Ferrão et al. (2009) ao avaliarem diferentes relações entre volumoso:concentrado (100:0; 75:25 e 50:50), observaram que o total de ácidos graxos monoinsaturados não foi influenciado pelos níveis energéticos das rações, apresentado valor médio de 42,32\%.

Os resultados de trabalhos mostram que é possível aumentar o teor de ácidos graxos poliinsaturados mediante alterações nas dietas. Entretanto, a elevação destes ácidos graxos deve ser observada com cautela, uma vez que, ser for em grande quantidade, pode ocasionar rancificação oxidativa na carne, o que reduzirá sua palatabilidade e, conseqüentemente, seu valor comercial. Produtos da oxidação de lipídios podem estar associados com sabores e odores desagradáveis, perda de cor e comprometimento da segurança da carne como alimento (Cifune et al., 2000).

INFLUÊNCIA DA CLASSE SEXUAL NA COMPOSIÇÃO DEÁCIDOS GRAXOS

Na literatura a uma escassez de trabalhos avaliando os efeitos das diferentes classes sexuais sobre o perfil lipídico da carne de ovinos. O sexo é um fator intrínseco ao animal que separa as carcaças ovinas entre fêmeas, machos castrados e machos inteiros. Tem sido incluído como parâmetro em muitos sistemas de tipificação de carcaças tendo em vista que as diferenças não só no rendimento de carne, mas também na qualidade da carne produzida (Cezar e Souza, 2007).

Em geral, as fêmeas de cordeiros depositam mais gordura distribuída nas regiões lombares e ventrais da carcaça em comparação aos machos (Sañudo et al., 1997). Lopez et al. (1991) relataram que, dentro de uma mesma raça, o efeito do sexo sobre a composição tecidual pode acentuar-se com o peso de abate e verificaram que as fêmeas depositaram mais tecido adiposo que os machos. As fêmeas apresentam carcaças fisiologicamente mais maduras, os castrados situam-se em uma condição intermediária e os machos inteiros, em condição mais tardia (Carvalho, 1998). Assim, a proporção de gordura é maior nas fêmeas, intermediária nos castrados e me- 
nores nos inteiros, ocorrendo o contrário com a proporção de músculo na carcaça (Cezar e Souza, 2007).

Tejeda, Penã e Andrés ( 2008) ao avaliarem a influência do sexo sobre as características físico-químicas e sensoriais carne de cordeiro Merino, observaram que as diferenças sexuais na composição dos ácidos graxos da gordura intramuscular foram mínimas. Somente no músculo Longissimus lumborum foi detectado um ligeiro efeito em alguns ácidos graxos minoritários (C17:0, C17:1 e C24:0), e em C18:2 (n-6) e C20:4 (n-6) e, conseqüentemente, PUFA total, foi maior nas fêmeas do que no sexo masculino. O que esta de acordo com Díaz et al. (2003) que encontraram altos níveis de C18:2 e AGPI total no sexo feminino. No entanto, Nürnberg et al. (1998) observou o efeito oposto. Em qualquer caso, o efeito do sexo sobre a composição lipídica está relacionada com o peso de abate de cordeiros, sendo mínimo este efeito em animais jovens, com menor peso vivo (Allen, 1970).

Dessa forma a gordura afeta a composição em ácidos graxos, porque os triacilgliceróis, que aumentam com a gordura, são mais saturada do que a constante fosfolipídios nas membranas do músculo (Marmer, Maxwell e Williams, 1984).

Pesquisando os efeitos do sexo sobre a composição centesimal e o perfil de ácidos graxos do músculo Semimembranosus (SM) de ovinos submetidos às mesmas condições de confinamento, Madruga et al. (2006), observaram que o sexo não influenciou significativamente as concentrações totais dos ácidos graxos saturados, monoinsaturados e poliinsaturados e nem as relações AGPI/AGS e $\omega 6: \omega 3$ da carne de ovinos. O teor do principal ácido graxo (C18:1), o qual tem influência direta no teor de colesterol da carne, foi superior nas fêmeas com concentração de C18:1 de 35,57 \%, em relação ao dos machos (32,02 \%).

De acordo com os resultados supracitados, Bass et al., 2007 também não encon- traram efeito do sexo sobre a composição de ácidos graxos, durante o período de terminação recebendo suplementação com linhaça.

Em contrapartida, Lind et al. (2011) ao estudarem o efeito do sexo sobre a qualidade da carne em cordeiro, observaram que o total de AGS e AGPI foi maior nos machos em relação as fêmea. Já o C16:0 foi superior nas fêmeas que em machos. Em contraste com este estudo, Díaz et al. (2003) relataram que fêmeas apresentaram maior teor de AGPI do que o macho enquanto Sañudo et al. (1998) não encontraram diferenças no conteúdo de AGPI entre sexos.

Okeudo e Moss (2007) ao estudarem o perfil de ácidos graxos do m. longissimus dorsi de ovinos com sexos diferenciados (castrado, inteiro, vasectomizado e ovelha), constataram que o teor de gordura intramuscular de lipídios variou de $1,9 \%$ para 2,5 $\%$ em todos os quatro tipos de sexo. O ácido graxo C18:1 foi o mais abundantes e responsáveis por quase metade do total. O outro ácido graxos de maior expressão foram ácido palmítico (16:0), 21,2 \% a 24,3 \%; esteárico(18:0), 16,9\% a 19,1\% e o C18:2, 3,2 $\%-4,5 \%$, e em conjunto com o ácidos graxo C18:1, eles responderam por mais de $90 \%$ do total. A proporção C18:3 representa de 0,8 \% a 1,1 \% do total de ácidos graxos. Há, no entanto, consenso geral de que machos inteiros têm menor teor de gordura subcutânea e intermuscular que as fêmeas e machos castrados (Wood et al., 1986 ).

Assim, quando a fase final do crescimento ocorre em confinamento, à base de rações com alto conteúdo de energia, os animais de maturidade precoce, especialmente as fêmeas, logo atingem a etapa de crescimento na qual a maior proporção da energia é depositada em forma de gordura. Conseqüentemente, esses animais devem ser abatidos mais jovens e leves, para evitar a produção excessiva de gordura. Por outro lado, os machos inteiros podem manter um conteúdo menor de gordura, mesmo com maiores pesos (Sainz, 2000). 
Diante dos resultados encontrados na literatura verifica-se que as diferenças na composição de ácidos graxos entre animais de sexo diferente têm sido inconsistentes, uma vez que o efeito do fator sexo na composição de ácidos graxos tem sido associado muito mais à fração de ácidos graxos do triglicerídeos (neutros) que à dos fosfolipídios (Banskalieva et al., 2000).

\section{INFLUÊNCIA DO GENÓTIPO NA COMPOSIÇÃO DEÁCIDOS GRAXOS}

A genética influencia a composição dos ácidos graxos, mas em menor grau do que os fatores dietéticos (De Smet et al., 2004). A variabilidade genética esta diretamente relacionado com as diferenças entre espécies, entre raças ou linhas, a variação devido ao cruzamento de raças e a variação entre os animais dentro das raças.

É complexo avaliar a real contribuição da genética sobre a composição lipídica da carne quando o parâmetro é a raça porque as comparações são muitas vezes confundidas por outros parâmetros, como peso de abate, idade e sistema de produção (Fisher et al., 2000).

De acordo com Sink e Caporaso (1977) estudos sobre a carne de carneiro e cordeiro indicam uma grande variação entre as raças, merecendo especial atenção uma vez que outros fatores possam produzir resultados equivocados por não considerarem outros atributos, como por exemplo, peso ao abate.

Em experimento onde os efeitos da raça e peso ao abate sobre o perfil e acúmulo de ácidos graxos no tecido adiposo subcutâneo foram estudados, Webb et al., (1994), verificaram que a espessura do tecido adiposo subcutâneo diferiu entre raças, e aumentou com o aumento do peso de abate. A raça influenciou a proporção dos ácidos mirístico (C14:0), heptadecanoico (C17:1) e oléico (C18:1 cis ). Já as concentrações de ácidos graxos (C14:0, C16:0, C16:1, C18:0 e C18:1) aumentaram com o aumento de peso vivo.

Diante dos parâmetros intrínsecos da genética, a espécie é relatada como a principal fonte de variação em termos de determinação da composição de ácido graxos da carne (De Smet et al., 2004). Pois, a carne de cordeiro normalmente têm uma baixa relação AGPI:AGS em comparação com carne de suínos, devido a biohidrogenação ruminal dos AGI.

Enser et al. (1996) relataram uma relação de AGPI:AGS de 0,11, 0,15 e 0,58 para a carne de bovinos, cordeiro e suínos, respectivamente. Embora a proporção de n-6:n-3 PUFA foi melhor para a carne de cordeiro em comparação com carne de bovinos e de porco $(2,11,1,32$ e 7,22, respectivamente).

O efeito da raça no perfil de ácido graxos da carne pode ser confundido por diferenças na gordura da carcaça (De Smet et al., 2004). Apesar disso, diferenças significativas nas concentrações individuais de ácido graxos entre as raças, e nas frações fosfolipídeos e triacilgliceróis foram relatados.

Madruga et al. (2006) ao avaliarem os efeitos do genótipo (Santa Inês e Santa Inês x Dorper) sobre a composição centesimal e o perfil de ácidos graxos do músculo Semimembranosus (SM) de ovinos, verificaram que os animais mestiços SI-D apresentaram maior percentual de AGPI, com alta concentração do ácido linoléico. Segundo os autores estas diferenças provavelmente se justificam pelo fato de ovinos Dorper serem considerados precoces em acabamento, tendendo a depositar gordura saturada em idade mais jovem, diminuindo os fosfolipídios da membrana, principalmente quando criados em confinamento (Wood et al., 2003). Quanto a relação AGPI/AGS, os animais da raça SI diferiram dos mestiços SI-D, com valores de 0,28 e 0,44 respectivamente, demonstrando que o cruzamento Santa Inês x Dorper melhorou o perfil lipídico da carne de cordeiros Santa Inês. A carne de cordeiros SI-D também se sobressaiu significativamente na relação $\omega 6: \omega 3$, a qual apresentou menor valor $(0,05)$ quando comparada à de SI $(0,09)$. Além disso, a carne ovina, nos três grupos, 


\section{INFLUÊNCIA DA DIETA, SEXO E GENÓTIPO SOBRE OS LIPÍDOS DA CARNE OVINA}

Tabela II. Composição de ácidos graxos (\%) de diferentes genótipos. (Fatty acid composition (\%) of different genotypes).

\begin{tabular}{lccc}
\hline & \multicolumn{3}{c}{ Genótipos } \\
Ácidos graxos & $\begin{array}{c}\text { Morada } \\
\text { Nova }\end{array}$ & $\begin{array}{c}\text { Santa } \\
\text { Inês }\end{array}$ & DxSI \\
\hline Monoinsaturados (AGM) & $32,20^{\mathrm{c}}$ & $32,68^{\mathrm{b}}$ & $33,90^{\mathrm{a}}$ \\
Saturados (AGS) & $60,24^{\mathrm{a}}$ & $60,08^{\mathrm{a}}$ & $58,66^{\mathrm{b}}$ \\
Poliinsaturados (AGP) $^{12,26^{\mathrm{b}}}$ & $12,76^{\mathrm{a}}$ & $11,82^{\mathrm{c}}$ \\
AGD $^{1}$ & $69,44^{\mathrm{b}}$ & $70,74^{\mathrm{a}}$ & $70,78^{\mathrm{a}}$ \\
\hline
\end{tabular}

Adaptado Batista (2008). ${ }^{1}$ Ácidos graxos.

Desejáveis $=$ AGM+AGP+C18:0.

apresentou a relação $\omega 6: \omega 3$ bem abaixo do mínimo recomendado, que deve ser inferior a 4, quando visa eliminar fatores de riscos de doenças como câncer e as doenças coronárias, associados à alimentação (Wood et al., 2003; Banskalieva et al., 2000).

Em contrapartida, Pelegrini et al.(2007) ao estudarem o perfil de ácidos graxos de ovelhas de descarte de dois grupos genéticos (Ideal e Texel), não observaram efeito do grupo genético no perfil de ácidos graxos e na proporção de ácidos graxos $\omega 6 / \omega 3$. Os principais ácidos graxos presentes no Longissimus das ovelhas foram o oléico

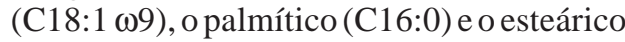
(C18:0), os quais representaram em torno de $75 \%$ da gordura total em todos os tratamentos.

O efeito do genótipo sobre o perfil lipídico pode ser observado no trabalho de Batista (2008) (tabela II), o qual avaliou animais da raça Morada Nova, Santa Inês e mestiços Dorper x Santa Inês, e verificaram maiores concentrações de AGM para os animais mestiços, com valores de 33,90\%. Porém os valores de AGS foram superiores para os animais puros. Já para os AGPI os animais da raça Santa Inês foram os que apresentaram maiores valores, seguidos da raça Morada Nova e os cruzados. A autora concluiu que o mestiço Dorper x Santa Inês apresentaram os índices mais desejáveis nas relações avaliadas, indicando um melhor perfil nutricional.

Costa (2005), ao estudarem a influência do cruzamento genético entre as raças Dorper e Santa Inês, constataram que o grupo genético Santa Inês apresentou valores superiores de ácido graxo monoinsaturado (46,71\%) e poliinsaturado (7,66 $\%)$ em ambos os cortes. Enquanto o grupo Dorper apresentou valores superiores de ácidos graxos saturados (43,63\%). Quanto ao teor de ácidos graxos poli-insaturados o ácido graxo linoléico (18:2- $\omega 6)$ apresentou variação de 1,01 a 2,04 \%.

Marino et al., 2008 ao avaliarem o efeito do genótipo (Altamurana e Trimeticcio), verificaram que o genótipo teve um menor impacto na composição de ácidos graxos em comparação com idade ao abate. A carne do músculo de cordeiros Trimeticcio apresentaram menor teor de ácido mirístico e maior teor de araquidônico e $\omega$-6 ácidos graxos (14,79\% vs 12,08\%) que Altamurana, que pode ser devido a diferenças no teor de gordura do leite de ovelhas Altamurana e Trimeticcio. Carne de cordeiros Trimeticcio e Altamurana apresentaram maior teor de ácidos graxos poliinsaturados do que os valores relatados por Diaz et al. (2005) em cordeiros Rasa Aragonesa (15,58 \%).

De forma semelhante, Salvatori et al. (2004) constataram que o genótipo afetou a composição de ácidos graxos da gordura intramuscular em cordeiro de duas raças mestiças A (Ile deFrancexPagliarol) e B (Gentile di PugliaxSopravissana) criados extensivamente. Assim, a proporção MUFA foi maior no genótipo A do que no genótipo $\mathrm{B}$, principalmente devido à maior proporção de C18:1 $\omega 9$. Em contrapartida, a proporção de ácidos graxos saturados foi maior em $\mathrm{B}$ do que no genótipo $\mathrm{A}$, devido à maior proporção de ácidos graxos C12:0, C14:0 e C16:0. Os teores de PUFA foram similares nos dois genótipos, apesar de C18:3 $\omega 3$ ter sido maior no genótipo A do que no genótipo B. Segundo os autores do ponto de vista da nutrição humana, o genótipo A (Ile de France 
$\times$ Pagliarola) apresentou o melhor perfil de ácidos graxos em todos músculos analisados. Na carne de mestiço, os resultados mostraram uma menor quantidade de ácidos graxos saturados (láurico e mirístico), uma maior percentagem de ácido oléico, uma maior proporção de ácidos graxos poliinsaturados linolênico e araquidônico. No entanto os resultados não indicam qualquer efeito significativo dos genótipos sobre o colesterol sérico, apresentando valor médio de 73,2 e 82,5 mg/100 g para os cruzamento A e B respectivamente.

Perez et al. (2002) determinaram a composição de ácidos graxos de tecidos de cordeiros Santa Inês e Bergamácia e verificaram que a porcentagem total de ácidos graxos saturados foi semelhante para todas as raças. O C18:1 $1 \omega 9$ e o total de ácidos graxos monoinsaturados foram maiores na raça Santa Inês e em ambas as raças aumentaram linearmente com o aumento do peso, entretanto, o total de ácidos graxos poliinsaturados das duas raças teve sua quantidade decrescida com o aumento do peso ao abate.

Diante da diversidade de resultados, é possível perceber que o conhecimento da importância quantitativa dos fatores que influenciam a composição de ácidos graxos é necessário, pois leva o pesquisador a escolher corretamente os parâmetros que podem produzir efeito de confundimento em suas pesquisas. Diante dessa preocupação, Juárez et al., 2008 tiveram como

\section{BIBLIOGRAFIA}

Allen, J.J. 1970. The effect of sex, weight and stress on carcass composition, fatty acid variability and organoleptic evaluation of lamb. PhD Thesis. University of Wyoming. USA.

Arruda, P.C.L. 2010. Teor de lipídeos totais, colesterol e perfil de ácidos graxos na carne de cordeiros da raça santa Inês alimentados com diferentes níveis energéticos. Dissertação (Mestrado). Universidade Federal do Ceará. Centro de Ciências Agrárias. Fortaleza. objetivo principal quantificar a influência da localização anatômica do depósito, depósito de gordura, raça, sistema de alimentação (desmame) e efeitos de gordura na composição da gordura de borregos espanhóis (Grazalema Merino, Churra, Spanish Merino, Montesina e Segurenã) e verificaram que a variação nos níveis AGS e AGPI e a relação n-3/n-6 foi explicada principalmente pela localização anatômicas do depósito (48,9\%, 78,7 \% e 80,0 \% respectivamente). O depósito de gordura foi o principal fator contribuindo para a variação nos níveis C16:1 e C18:0 (32,0 \% e 31,8\%, respectivamente). Os autores concluíram que o sistema de produção, em combinação com raça e dieta, foi o principal fator para explicar variações na perfil de ácidos graxos de carne de ovinos.

\section{CONCLUSÃO}

A modernização nas técnicas de produção de alimentos tem propiciado relevantes avanços na pesquisa científica. Considerando os anseios dos mercados consumidores de carne, estratégias alimentares, genéticas e ou de gênero produzem resultados variados no que concerne ao produto final carne. Dessa forma a quantificação precisa dos efeitos dos fatores interferentes poderão elucidar antigas dúvidas bem como poderão direcionar as pesquisas na produção de alimentos benéficos para saúde humana.

Banskalieva, V.; Sahlu, T. and Goetsch, A.L. 2000. Fatty acid composition of goat muscles and fat depots a review. Small Ruminant Res, 37: 255268.

Bass, P.; Berthelot, V.; Pottier, E., and Normand, J. 2007. Effect of linseed on fatty acid composition of muscles and adipose tissues of lambs with emphasis on trans fatty acids. Meat Science, 77: 678-688.

Batista, A.S.M. 2008.Qualidade de carne de ovinos 


\section{INFLUÊNCIA DA DIETA, SEXO E GENÓTIPO SOBRE OS LIPÍDOS DA CARNE OVINA}

Morada Nova, Santa Inês e mestiços Dorper x Santa Inês submetidos a dietas com diferentes concentrações energéticas. Tese (Doutorado em Zootecnia). Universidade Federal da Paraíba. Centro de Ciências Agrárias. Areia. 127 pp.

Boles, J.A.; Kott, R.W.; Hatfield, P.G.; Bergman, J.W. and Flynn, C.R. 2005. Supplemental safflower oil affects the fatty acid profile, including conjugated linoleic acid of lamb. J Anim Sci, 83: 2175-2181.

Bonanome, A. and Grundy, S.M. 1988. Effects of dietary stearic acid on plasma cholesterol and lipoprotein levels. New Engl J Med, 318: 12441248.

Caputi Jambrenghi, A.; Paglialonga, G.; Gnoni, A.; Zanotti, F.; Giannico, F. and Vonghia, G. 2007. Changes in lipid composition and lipogenic enzyme activities in liver of lambs fed n_6 polyunsaturated fatty acids. Comp Biochem Physiol B, 147: 498-503.

Carvalho, S. 1998. Desempenho, composição corporal e exigências nutricionais de cordeiros machos inteiros, machos castrados e fêmeas alimentados em confinamento. Dissertação (Mestrado em Zootecnia). Universidade Federal de Santa Maria. Santa Maria. 102 pp.

Cezar M.F. e Souza W.H. 2007. Carcaças ovinas e caprinas: obtenção, avaliação e classificação. Editora Agropecuária Tropical. Uberaba, M.G. $147 \mathrm{pp}$.

Choi, N.J.; Enser, M.; Wood, J.D. and Scollan, N.D. 2000. Effect of breed on the deposition in beef muscle and adipose tissue of dietary n-3 polyunsaturated fatty acids. Anim Sci, 71: 509-519.

Cifune, G.F.; Napolitano, F.; Pacelli, C.; Riviezzi, A.M. and Girolami, A. 2000. Effect of age at slaughter on carcass traits, fatty acid composition and lipid oxidation of Apulian lambs. Small Ruminant Res, 35: 65-70.

Cooper, S.L.; Sinclair, L.A.; Wilkinson, R.G.; Hallett, K.G.; Enser, M. and Wood, J.D. 2004. Manipulation of the $n-3$ polyunsaturated fatty acid content of muscle and adipose tissue in lambs. J Anim Sci, 82: 1461-1470.

Costa, M.M. 2005 Efeito do cruzamento genético (Dorper x SRD e Santa Inês x SRD) e do tratamento nutricional - idade de abate sobre a composição centesimal e lipídica dos cortes lombo e pernil. Dissertação (Mestrado). Universidade Federal do Ceará. Fortaleza. $91 \mathrm{f}$.
Costa, R.G.; Cartaxo, F.G.; Santos, N.M. e Queiroga, R.C.R.E. 2008. Carne caprina e ovina: composição lipídica e características sensoriais. Rev Bras Saúde e Prod Anim, 9: 497-506.

De Smet, S.; Raes, K. and Demeyer, D. 2004.Meat fatty acid composition as affected by fatness and genetic factors: a review. Anim Res, 53: 81-98.

Demeyer, D. and Doreau, M. 1999. Targets and procedures for altering ruminant meat and milk lipids. Proc Nutr Soc, 58: 593-607.

Demirel, G.; Ozpinar, H.; Nazli, B. and Keserl, O. 2006. Fatty acids of lamb meat from two breeds fed different forage: concentrate ratio. Meat Sci, 72: 229-235.

Demirel, G.; Wachira, A.M.; Sinclair, L.A.; Wilkinson, R.G.; Wood, J.D. and Enser, M. 2004. Effects of dietary n_3 polyunsaturated fatty acids, breed and dietary vitamin $\mathrm{E}$ on the fatty acids of lamb muscle, liver and adipose tissue. Brit J Nutr, 91: 551-565.

Díaz, M. T.; Velasco, S.; Pérez, C.; Lauzurica, S.; Huidobro, F. and Cañeque, V. 2003. Physicochemical characteristics of carcass and meat Manchego-breed suckling lambs slaughtered at different weights. Meat Sci, 65: 1085-1093.

Díaz, M.T.; Álvarez, I.; De La Fuente, J.; Sañudo, C.; Campo, M.M.;Olivier, M.A.; Font, I.; Furnols, M.; Montossi, F.; San Julián, R.; Nute, G.R. and Cañeque, V. 2005. Fatty acids composition of meat from typical lamb production systems of Spain, United Kingdom, Germany and Uruguay. Meat Sci, 71: 256-263.

Díaz, M.T.; Velasco, S.; Cañeque, V.; Lauzurica, S.; Huidobro,F.R.; Pérez, C.; González, J. and Manzanares, C. 2002. Use of concentrate or pasture for fattening lambs and its effect on carcass and meat quality. Small Ruminant Res, 43: 257-268.

Enser, M.; Hallett, K. and Hewitt, B.1996. Fatty acid content and composition of English beef, lamb and pork at retail. Meat Sci, 42: 443-456.

Farfan, J.A.1996. Alimentos que influenciam os níveis de colesterol no organismo. Seminário Colesterol: Análise, Ocorrência, Redução. Em: Alimentos e Implicações $\mathrm{Na}$ Saúde, [s.n.]. Anais... Campinas. Italia. pp. 35-44.

Fernandes, M.; Monteiro, A.M.; Candal Poli, A.L. G.; Barros, C.H.E.; Almeida, C.S.R. e Ribeiro, T. M.D. 2010. Composição tecidual da carcaça e 


\section{OLIVEIRA, RODRIGUES, OLIVEIRA, ALMEIDA,GARCIAE OLIVEIRA}

perfil de ácidos graxos da carne de cordeiros terminados a pasto ou em confinamento. Rev Bras Zootecn, 39: 1600-1609.

Fernandes, S.A.A.; Mattos, W.R.S.; Matarazzo, S.V.; Gama, M.A.S.; Lanna, D.P.D.; Rosseto, C.V. 2007.Perfil de ácidos graxos em alimentos de clima tropical utilizados nas dietas para ruminantes. Bol Indústr Anim, 64: 19-27.

Ferrão, S.P.B.; Bressan, M.C.; Oliveira, R.P.; Pérez, J.R.O.; Rodrigues, E.C. e Nogueira, D.A. 2009. Características sensoriais da carne de cordeiros da raça Santa Inês submetidos a diferentes dietas. Ciênc Agrotec, 33: 185-190.

Fisher, A. V.; Enser, M.; Richardson, R.I.; Wood, J. D.; Nute, G.R. and Kurt, E. 2000. Fatty acid composition and eating quality of lamb types derived from four diverse breed $x$ production systems. Meat Sci, 55:141-147.

French, P.; Stanton, C.; Lawless, F.; O'Riordan, E.G.; Monahan, F.J.; Caffrey, P J. and Moloney, A.P. 2000. Fatty acid composition, including conjugated linoleic acid, of intramuscular fat from steers offered grazed grass, grass silage, or concentrate-based diets. J Anim Sci, 78: 2849-2855.

Gallo, S.B.; Siqueira, E.R.; Rosa, G.T.I. 2007. Efeito da nutrição da ovelha e do cordeiro sobre o perfil de ácidos graxos do músculo Triceps brachii de cordeiros. Rev Bras Zootecn, 36: 2069-2073.

Harfoot, C.G.; Hazlewood, G.P. 1997. Lipid metabolism in the rumen. In: HOBSON, P.N. (Ed.) The rumen microbial ecosystem. London: Elsevier, 285-322.

Ip, C.; Singh, M.; Thompson, H. J. and Scimeca, J. A. 1994. Conjugated linoleic acid suppresses mammary carcinogenesis and proliferative activity of the mammary gland in the rat. Cancer Res, 54: 1212-1215.

Jenkins, T.C.1993. Lipid metabolism in the rumen. J Dairy Sci, 76: 3851-3863.

Joy, M.; Ripoll, G. and Delfa, R. 2008. Effects of feeding system on carcass and non-carcass composition of Churra Tensina light lambs. Small Ruminant Res, 78: 123-133.

Juárez, M.; Horcada, A.; Alcalde, M.J.; Valera, M.; Mullen, A.M. and Molina, A. 2008. Estimation of factors influencing fatty acid profiles in light lambs. Meat Sci, 79: 203-210.

Khanal, R.C. and Dhiman, T.R. 2004. Biosynthesis of conjugated linoleic acid (CLA): a review. Pak J Nutr, 3: 72-81.

Kouba, M. and Mourota, J. 2011. A review of nutritional effects on fat composition of animal products with special emphasis on $\mathrm{n}-3$ polyunsaturated fatty acids. Biochimie, 93: 13-17.

Laborde, F.L.; Mandell, I.B.; Tosh, J. J.; Wilton, J.W. and Buchanan-Smith, J.G. 2001. Breed effects on growth performance, carcass characteristics, fatty acid composition, and palatability attributes in finishing steers. J Anim Sci, 79: 355-365.

Lehninger, A.L. 1990. Principios de bioquímica. Traduzido por Lodi, W.R.; Simões, A.A. Editora Savier. São Paulo. 723 pp.

Lind, V.; Berg, J.; Eilertsen, S. M.; Hersleth, M. and Eik, L.O. 2011. Effect of gender on meat quality in lamb from extensive and intensive grazing systems when slaughtered at the end of the growing season. Meat Sci, 88: 305-310.

Lopez M.; Colomer, F. y Rodríguez, M. 1991. Producción de carne en la raza Lacha. I. Rendimento de la canal y componentes del quinto quarto de lechales, ternascos y corderos. Jornadas Científicas de la Sociedad Española de Ovinotecnia y Caprinotecnia (SEOC). Resúmenes... Pamplona. pp. 433-441.

Macedo, V.P.; Garcia, C.A.; Silveira A.C.; Monteiro, A.L.G.; Macedo,F.A.F. e Spers, R.C. 2008. Composições tecidual e química do lombo de cordeiros alimentados com rações contendo semente de girassol em comedouros privativos. Rev Bras Zootecn, 37: 1860-1868.

Madruga, M.S.; Araújo, W.O.; Sousa, W.H.; Cézar, M.F.; Galvão, M.S. e Cunha, M.G.G. 2006. Efeito do genótipo e do sexo sobre a composição química e o perfil de ácidos graxos da carne de cordeiros. Rev Bras Zootecn, 35: 1838-1844.

Madruga, M. S.; Sousa, W.H.; Rosales, M.D.; Cunha, M.G.G.; Ramos, J.L.F. 2005. Qualidade da carne de cordeiros Santa Inês terminados com diferentes dietas. Rev Bras Zootecn, 34: 309-315.

Madruga, M.S.; Vieira, T.R.L.; Cunha, M.G.G.; Pereira Filho, J.M.; Queiroga, R.C.R.E. e Sousa, W.H. 2008. Efeito de dietas com níveis crescentes de caroço de algodão integral sobre a composição química e o perfil de ácidos graxos da carne de cordeiros Santa Inês. Rev Bras Zootecn, 37: 1496-1502.

Manso, T.; Bodas, R.; Castro, T.; Jimeno, V. and 


\section{INFLUÊNCIA DA DIETA, SEXO E GENÓTIPO SOBRE OS LIPÍDOS DA CARNE OVINA}

Mantecon, A.R. 2009. Animal performance and fatty acid composition of lambs fed with different vegetable oils. Meat Sci, 83: 511-516.

Marino, R.; Albenzio, M.; Annicchiarico, G.; Caroprese, M.; Muscio, A.; Santillo, A. and Sevi, A. 2008. Influence of genotype and slaughtering age on meat from Altamurana and Trimeticcio lambs. Small Ruminant Res, 78: 144-151.

Marmer, W.N.; Maxwell, R.J. and Williams, J.E. 1984. Effects of dietary regimen and tissue site on bovine fatty acid profiles. J Anim Sci, 59: 109-121.

Nuernberg, K.; Fischer, A.; Nuernberg, G.; Ender, K. and Dannenberger, D. 2008. Meat quality and fatty acid composition of lipids in muscle and fatty tissue of Skudde lambs fed grass versus concentrate. Small Ruminant Res, 74: 279-283.

Nürnberg, K..; Wegner, J. and Ender, K. 1998. Factors influencing fat composition in muscle and adipose tissue of farm animals. Livest Prod Sci, 56: 145-156.

Okeudo, N.J. and B.W. Moss. 2007. Intramuscular lipid and fatty acid profile of sheep comprising four sex-types and seven slaughter weights produced following commercial procedure. Meat Sci, 76: 195-200.

Palmquist, D.L.; Weisbjerg, M.R.; Hvelplund, T. 1993. Ruminal, intestinal, and total digestibilities of nutrients in cows fed diets high in fat and undegradable protein. J Dairy Sci, 76: 13531364.

Pariza M.W.; Park Y. and Cook M.E. 2001. The biologically active isomers of conjugated linoleic acid. Prog Lipid Res, 40: 283-98.

Parodi, P.W. 2003. Conjugated linoleic acid in food. In: Sebedio, J.; Christie, W.W.; Adlof, R. (Eds.). Advances in conjugated linoleic acid research. AOCS Press. Champaign, II. Vol. 2: 101-121.

Pelegrini, L.F.V.; Pires, C.C.; Kozloski, Terra, G.V. N.N.; Baggio, S.R.; Campagnol, P.C.B.; Galvani, D.B. e Chequim, R.M. 2007. Perfil de ácidos graxos da carne de ovelhas de descarte de dois grupos genéticos submetidas a dois sistemas de manejo. Ciênc Rural, 37: 1786-1790.

Pérez, J.R.O.; Bressan, M.C.; Bragagnolo, N.; Prado, O.V.; Lemos, A.L.S.C. e Bonagurio, S. 2002. Efeito do peso ao abate de cordeiros Santa Inês e Bergamácia sobre o perfil de ácidos graxos, colesterol e propriedades quími- cas. Ciênc Tecnol Aliment, 22: 11-18.

Raes, K.; Balcaen, A.; Balcaen, P.; Winne, A. de; Claeys, E.; Demeyer, D. and Smet, S. de. 2003. Meat quality, fatty acid composition and flavor analysis in Belgian retail beef. Meat Sci, 65: 1237-1246.

Raes, K.; De Smet, S. and Demeyer, D. 2004. Effect of dietary fatty acids on incorporation of long chain polyunsaturated fatty acids and conjugated linoleic acid in lamb, beef and pork meat: a review. Anim Feed Sci Technol, 113: 199-221.

Sainz, R.D. 2000. Avaliação de carcaças e cortes comerciais de carne caprina e ovina. Simpósio Internacional Sobre Caprinos e Ovinos de Corte. JoãoPessoa, PB. Anais... pp: 237-250.

Salvatori, G.; Pantaleo, L.; Di Cesare C.; Maiorano, G.; Filetti, F. and Oriani, G. 2004. Fatty acid composition and cholesterol content of muscles as related to genotype and vitamin $\mathrm{E}$ treatment in crossbred lambs. Meat Sci, 6: 45-55.

Sañudo, C.; Sanchez, A. and Alfonso, M. 1998. Small ruminant production systems and factors affecting lamb meat quality. Meat Sci, 49: S29S64.

Sañudo, C.; Campo, M. M.; Sierra, I. María, G.A.; Olleta, J.L. and Santolaria, P. 1997. Breed effect on carcass and meat quality of suckling lambs. Meat Sci, 46: 357-365.

Sink, J. D. and Caporaso, F. 1977. Lamb and mutton flavour: contributing factors and chemical aspects. Meat Sci, 1: 119-127.

Tejeda, J.F.; Peña, R.E. and Andrés, A.I. 2008. Effect of live weight and sex on physic-chemical and sensorial characteristics of Merino lamb meat. Meat Sci, 80: 1061-1067.

Tricon, S.; Burdge, G.C.; Williams, C.M.; Calder, P.C. and Yaqoob, P. 2005. The effects of conjugated linoleic acid on human health-related outcomes. Proc. Nutr Soc, 64: 171-182.

Velasco, S.; Cañeque, V.; Lauzurica, S.; Pérez, C. and Huidobro, F. 2004. Effect of different feeds on meat quality and fatty acid composition of lambs fattened at pasture. Meat Sci, 66: 457-465.

Wachira, A.M.; Sinclair, L.A.; Wilkinson, R.G.; Enser, M.; Wood, J.D. and Fisher, A.V. 2002. Effects of dietary fat source and breed on the carcass composition, n-3 polyunsaturated fatty acid and conjugated linoleic acid content of sheep meat and adipose tissue. British J Nutr, 


\section{OLIVEIRA, RODRIGUES, OLIVEIRA, ALMEIDA,GARCIAE OLIVEIRA}

88: 697-709.

Webb, E.C.; Casey, N.H. and Van Nierkerk, W.A. 1994. Fatty acids in the subcutaneous adipose tissue of intensively fed AS Mutton Merino and Dorper Wethers. Meat Sci, 38: 123-131.

Webb, E.C and O'Neill, H.A. 2008. The animal fat paradox and meat quality. Meat Sci, 80: 28-36.

Wood, J. D.; Enser, M.; Fisher, A.V.; Nute, G.R., Sheard, P.R.; Richardson, R.I.; Hughes, S.I. and Whittington, F.M. 2008. Fat deposition, fatty acid composition and meat quality: a review. Meat Sci, 78: 343-358.

Wood, J.D.; Fisher, A.V. and Whelehan, O.P. 1986. The effect of combined androgenic - oestrogenic anabolic agents in steers and bulls. 2. Muscle weight distribution, partition of body fat and carcass value. Anim Prod, 42: 213-222.

Wood, J.D.; Richardson, R.I.; Nute, G.R.; Fisher, A.V.; Campo, M.M.; Kasapidou, E.; Sheard, P.R. and Enser, M. 2003. Effects of fatty acids on meat quality: a review. Meat Sci, 66: 21-32.

Wood, J.D.; Enser, M. and Fisher, A.V.1999. Manipulating meat quality and composition. Proc Nutr Soc, 58: 363-370.

Wood, J.D.; Richardson, R.L. and Nute, G.R. 2003. Effects of fatty acids on meat quality: a review. Meat Sci, 66: 21-32.

Zembayashi, M.K.; Nishimura, D.K.; Lunt, S.B. and Smith. 1995. Effect of breed type and sex on the fatty acid composition of subcutaneous and intramuscular lipids of finishing steers and heifers. J Anim Sci, 73: 3325-3332. 